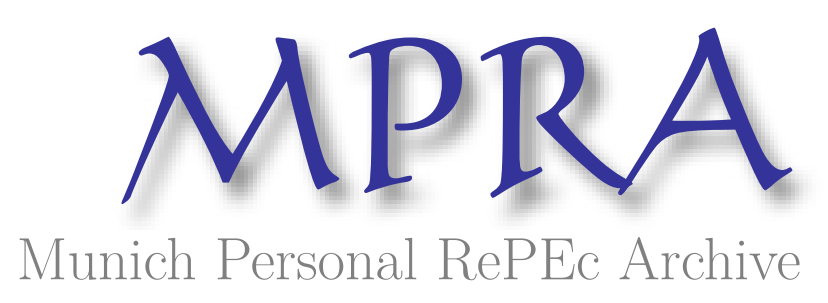

\title{
Administering Foreign-Worker Programs
}

Cebula, Richard

Jacksonville University

18 March 1982

Online at https://mpra.ub.uni-muenchen.de/58576/

MPRA Paper No. 58576, posted 14 Sep 2014 22:43 UTC 


\section{Administering Foreign-Worker Programs.}

By Mark J. Miller and Philip L. Martin. Lexington, Massachusetts and Toronto: Lexington Books, 1982. Pp. xvii, 194. \$21.95.

The issue of illegal aliens has received considerable attention in recent years. Concern over the problem of illegal aliens has promulgated an array of efforts by the federal government to examine and revise immigration statutes and practices. Indeed, much debate has arisen over the possibility of instituting a large scale temporary foreign worker program in the United States. The book by professors Miller and Martin addresses some of the basic problems that must be taken into consideration in administering such a foreign-worker program.

In this book, the basic means of generating relevant insights is to draw from the Western European experience with large-scale foreign-worker programs. The reasoning behind this approach is that if the United States were indeed to embark on a large-scale temporary foreign-worker program, it would be in effect be comparable with the post-World War II policies in Western Europe.

The book consists of some ten chapters. The writing style is fairly lucid, and the sequencing of the chapters and chapter topics is logical. The first chapter basically identifies the issue and outlines the approach of the book. Chapters 2 through 9 basically deal with the postwar Western European foreign-worker programs. The tenth chapter is the crucial chapter since it embodies the various implications that can be drawn from the proceeding eight chapters.

Chapter 10 in fact outlines and discusses four classifications of lessons to be derived from the Western European experience. These four classifications include: economic, administrative, socio-political and foreign policy. Although the inferences made by professors Miller and Martin are quite reasonable in all cases, the substantial issues of greatest concern may be those which are fundamentally economic in nature.

Among the many economic lessons discussed by Professors Miller and Martin, several stand out. They observe that the issue of which jobs are to be open to foreign-worker employment must be resolved. The issues of repatriation and potential United States citizenship must be addressed. In addition, the temporary-permanent job distinction must be appropriately clarified. The authors also note than an expanded foreign-worker policy will tend to foster a dual labor market. In addition, it is argued that, in time, the United States citizens may come to reject employment associated with foreign-worker programs as demeaning. If this attitude should in fact evolve, it would in fact create a certain labor-market dependency upon foreign workers. Of course, at a different level, foreign workers may conceivable contribute to economic dualism in labor-importing countries. Next, it is observed that foreign workers tend to increase employer profits. If in fact foreign workers are willing to work at existing money wage rates, employers can save on restructuring costs and thusly increase net income. In addition, since foreign workers typically save at significantly higher rates than do domestic citizens, inflationary pressures can be relieved by their presence. Finally, the very availability of foreign workers may at to dissuade private investment, especially during periods 
of greater uncertainty. This fact could, in the long run, generate supply-side inflationary pressures.

Overall, the book is well written and well organized. It also deals with a relevant issue and does so competently; all that is still needed is more quantification and information. The book is a worthwhile study.

Richard J. Cebula

Emory University 